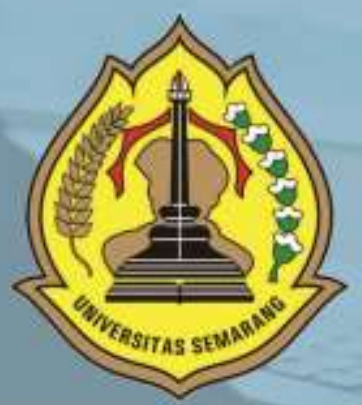

P-ISSN: 1412-5331, E-ISSN: 2716-2532 MAJALAH ILMIAH FAKULTAS EKONOMI UNIVERSITAS SEMARANG

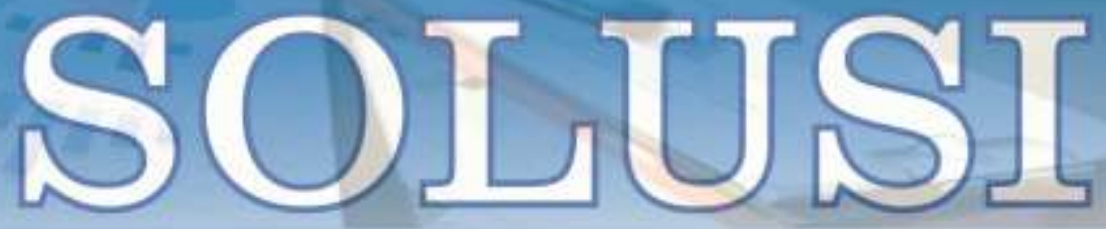

PENGARUH TINGKAT LITERASI KEUANGAN, SIKAP INDIVIDU TERHADAP MINAT INVESTASI SAHAM DI KALANGAN MAHASISWA S2 MAGISTER MANAJEMEN UNIVERSITAS SEMARANG (Asah Wiari Sidiq: Asih Niati - Universitas Semarang)

PENINGKATAN KINERJA PENGAJARAN DOSEN MELALUI KEPEMIMPINAN TRANSFORMASIONAL DAN PEMENUHAN KEBUTUHAN PSIKOLOGIS DASAR DENGAN PEMEDIASI MOTIVASI KER.JA (Anik Herminingsih - Universitas Mercu Buana)

PENGARUH PAJAK, TUNNELING INCENTIVE DAN GOOD CORPORATE GOVERNANCE (GCG) DAN MEKANISME BONUS TERHADAP INDIKASI TRANSFER PRICING PADA PERUSAHAAN MANUFAKTUR (Arum Sasi Andayani; Andiani Ika Sulistyanuati - Liniversitas Semarang)

PENGELOLAAN ALOKASI DANA DESA: AKUNTABILITAS DAN TRANSPARANSI (STUDI KASUS PADA DESA GINGGANGTANI, KECAMATAN GUBUG, KABUPATEN GROBOGAN) (Ana Rokhatt: Saifidin: Dian Trivani - Universitas Semarang)

PENERAPAN STRATEGI BAURAN PEMASARAN PADA USAHA KECIL TELUR ASIN DI KELURAHAN TEGAL SARI, KECAMATAN CANDI SARI, SEMARANG (Nisa Novia Avien Christy; Dwi Widi Pratito - Universitas Semarang)

FAKTOR-FAKTOR YANG MEMPENGARUHI PROFITABILITAS LEMBAGA PERKREDITAN DESA (LPD) DI KABUPATEN BADUNG (Ida Ayu Nyoman Yuliastuti, Putu Kepramareni, I Gusti Ayu Asta Yunisari - Universitas Mahasaraswati Denpasar)

KEBERHASILAN MEMPERTAHANKAN WARUNG MAKAN PRASMANAN MBAH SAN (Sri Wulandari: Susanto - Universitas Semarang)

BRAND PERSONALITY DAN GENDER BRAND PERSONALITY STRATEGI MEMBANGUN MEREK (Haris Murwanto - Universitas Semarang)

POLA PERMINTAN DAN PENAWARAN KETERSEDIAAN DAGING SAPI NASIONAL TAHUN 2030 DENGAN PENDEKATAN FORECASTING (Moeljono - Universitas Semarang)

PENGARUH BRAND IMAGE, KUALITAS PRODUK, PERSEPSI HARGA TERHADAP KEPUTUSAN PEMBELIAN (STUDI KASUS PADA PRODUK SUSU NATURSOYA CV. GLOBAL MANDIRI SEJAHTERA KANCA PURWODADI)

(Ajeng Ayr Fatimah P: Soedarmadi - Untversitas Semarang) 


\section{DESKRIPSI}

Majalah IImiah Solusi Mengkaji

Masalah-Masalah Sosial,

Ekonomi dan Bisnis

\section{KETERANGAN TERBIT}

Terbit Pertama Kali Juli 2002

dan SelanjutnyaTerbit Tiga Bulan

Sekali (Januari, April, Juli dan

Oktober)

\section{PENERBIT}

Fakultas Ekonomi USM

\section{ALAMAT PENERBIT}

JL. Soekarno Hatta Semarang

Telp. 024-6702757 Fax. 024-6702272

\section{PENGELOLA}

Editor in Chief : Yohanes Suhardjo, SE, M.Si., Ak, CA Vice Editor Chief : Sugeng Rianto, SE, MM

Managing Editor: Edy Suryawardana, SE, MM

Secretary of Managing Editor : Asih Niati, SE, MM

Administration \& Circulation :

Citra Rizkiana, SE, MM

Layout \& Typesetting : M Burhan Hanif S.Kom, M.Kom

Board of Editors:

1. Prof. Dr. Ir. Kesi Widjajanti, SE, MM (USM)

2. Prof. Drs. Mohammad Nasir, Msi, Ph.D, AK. (USM)

3. Prof. Supramono SE, MBA, DBA (UKSW)

4. Prof. Drs. H. Imam Ghozali, M.Com, Akt, PhD (UNDIP)

5. Prof. Dr. Agus Suroso, MS (UNSOED)

6. Prof. Dr. Widodo, SE, M.Si (UNISSULA)

7. Prof. Dr. Dra. Sulastri, ME, M.Kom (UNSRI)

8. Dr. Ardiani Ika S, SE, MM, Ak, CA, CPA (USM)

\section{KATA PENGANTAR}

Sungguh merupakan kebahagiaan tersendiri bagi kami, takala kami dapat hadir rutin setiap tiga bulan sekali untuk saling bertukar pikiran mengenai hal-hal baru dibidang sosial, ekonomi dan bisnis.

Pada kesempatan ini penerbit menyampaikan terima kasih kepada semua pihak yang telah mengirimkan artikel-artikelnya. Penerbit akan membuka kesempatan seluas-luasnya bagi seluruh kalangan akademisi maupun praktisi baik dari dalam maupun luar Universitas Semarang untuk mempublikasikan karya ilmiahnya.

Penerbitan majalah ilmiah "SOLUSI" kali ini menghadirkan 10 (Sepuluh) artikel yang kami anggap layak untuk diterbitkan, dengan harapan dapat menjadi tambahan referensi bagi para pembaca dan menjadi sumbangan pengembangan persemaian khasanah pengetahuan dibidang sosial, ekonomi dan bisnis.

Akhir kata semoga majalah ilmiah "SOLUSI" dapat memberi manfaat yang sebesar-besarnya.

Hormat Kami 


\section{DAFTAR ISI}

PENGARUH TINGKAT LITERASI KEUANGAN, SIKAP INDIVIDU

TERHADAP MINAT INVESTASI SAHAM DI KALANGAN MAHASISWA S2 MAGISTER MANAJEMEN UNIVERSITAS SEMARANG

(Asah Wiari Sidiq; Asih Niati - Universitas Semarang).......

PENINGKATAN KINERJA PENGAJARAN DOSEN MELALUI

KEPEMIMPINAN TRANSFORMASIONAL DAN PEMENUHAN KEBUTUHAN PSIKOLOGIS DASAR DENGAN PEMEDIASI MOTIVASI KERJA

(Anik Herminingsih - Universitas Mercu Buana)

PENGARUH PAJAK, TUNNELING INCENTIVE DAN GOOD CORPORATE GOVERNANCE (GCG) DAN MEKANISME BONUS TERHADAP INDIKASI TRANSFER PRICING PADA PERUSAHAAN MANUFAKTUR

(Arum Sasi Andayani; Ardiani Ika Sulistyawati - Universitas Semarang)

PENGELOLAAN ALOKASI DANA DESA: AKUNTABILITAS DAN TRANSPARANSI

(STUDI KASUS PADA DESA GINGGANGTANI, KECAMATAN GUBUG, KABUPATEN GROBOGAN)

(Ana Rokhati; Saifudin; Dian Triyani - Universitas Semarang).

PENERAPAN STRATEGI BAURAN PEMASARAN PADA USAHA KECIL TELUR ASIN DI KELURAHAN TEGAL SARI, KECAMATAN CANDI SARI, SEMARANG

(Nisa Novia Avien Christy; Dwi Widi Pratito - Universitas Semarang)

FAKTOR-FAKTOR YANG MEMPENGARUHI PROFITABILITAS LEMBAGA PERKREDITAN DESA (LPD) DI KABUPATEN BADUNG

(Ida Ayu Nyoman Yuliastuti; Putu Kepramareni; I Gusti Ayu Asta Yunisari - Universitas Mahasaraswati Denpasar)..... .75

KEBERHASILAN MEMPERTAHANKAN WARUNG MAKAN PRASMANAN MBAH SAN

(Sri Wulandari; Susanto - Universitas Semarang).....

BRAND PERSONALITY DAN GENDER BRAND PERSONALITY STRATEGI MEMBANGUN MEREK

(Haris Murwanto - Universitas Semarang).

POLA PERMINTAN DAN PENAWARAN KETERSEDIAAN DAGING SAPI NASIONAL TAHUN 2030 DENGAN PENDEKATAN FORECASTING

(Moeljono - Universitas Semarang)......

PENGARUH BRAND IMAGE, KUALITAS PRODUK, PERSEPSI HARGA TERHADAP KEPUTUSAN PEMBELIAN (STUDI KASUS PADA PRODUK SUSU NATURSOYA CV. GLOBAL MANDIRI SEJAHTERA KANCA PURWODADI)

(Ajeng Ayu Fatimah P; Soedarmadi - Universitas Semarang) 


\title{
PENGARUH PAJAK, TUNNELING INCENTIVE DAN GOOD CORPORATE GOVERNANCE (GCG) DAN MEKANISME BONUS TERHADAP INDIKASI TRANSFER PRICING PADA PERUSAHAAN MANUFAKTUR
}

\author{
Arum Sasi Andayani ${ }^{1}$ \\ Ardiani Ika Sulistyawati ${ }^{2}$ \\ ardiani@usm.ac.id ${ }^{2}$
}

Fakultas Ekonomi Universitas Semarang

Diterima: November 2019, Disetujui:Desember 2019,Dipublikasikan: Januari 2020

\begin{abstract}
Transfer pricing happen on the company with high profit purpose and using tax avoidance become the a to fulfil it. Ownership stucture is also affect management to transfer wealth the themeself or to majority stakeholder. The company that applying good corporate governance will not be able to make a profit manipulation. This study aimed to examine the effect of tax, tunneling incentive and good corporate governance on indication of transfer pricing. The sample used on this study is manufacturing company listed on the Indonesia Stock Exchange for years 2013-2015 totaling 42 companies, and the sample is taken by purposive sampling method. The analysis technique used on this study is a binary logistic regression with program SPSS 16.0 for windows. The result of this study shows that tax and bonus mechanism is not significantly effect on transfer pricing. Good corporate governance and tunneling incentive have significant to transfer pricing. The determination coefficient is 0.335 . This result show that $33,5 \%$ transfer pricing is affected by tax, tunneling incentive good corporate governance and bonus mechanism. While the rest is $66.5 \%$ explained by other variable that means many other variables in outside of tax, tunneling incentive, good corporate governance and bonus mechanism that can explain transfer pricing.
\end{abstract}

Keywords: Transfer Pricing, Tunneling Incentive, Good Corporate Governance, Tax, Bonus Mechanism.

\section{ABSTRAK}

Transfer Pricing dapat muncul pada perusahaan yang memiliki tujuan laba tinggi dan penghindaran pajak sebagai salah satu caranya. Struktur kepemilikan juga mempengaruhi manajemen untuk mengalihkan kekayaan kepada mereka sendiri atau pemegang saham mayoritas. Perusahaan yang menerapkan Good Corporate Governance cenderung tidak akan melakukan manipulasi laba. Penelitian ini bertujuan untuk meneliti pengaruh pajak, tunneling incentive, good corporate governance (GCG) dan mekanisme bonus terhadap indikasi melakukan transfer pricing pada perusahaan manufaktur yang terdaftar di Bursa Efek Indonesia. Sampel penelitian yang digunakan dalam penelitian ini adalah perusahaan manufaktur yang terdaftar di BEI periode 2013-2015 yang berjumlah 42 perusahaan dengan metode purposive sampling. Teknik analisis yang digunakan pada penelitian ini adalah regresi logistik dengan bantuan program komputer SPSS Versi 16,0. Hasil dari penelitian ini menunjukkan bahwa pajak dan mekanisme bonus tidak berpengaruh signifikan terhadap indikasi melakukan transfer pricing. Sementara good corporate governance dan tunneling incentive berpengaruh signifikan terhadap transfer pricing. Koefisien determinasi sebesar 0,335. Hasil ini menunjukkan bahwa 33,5\% transfer pricing dipengaruhi oleh variabel pajak, tunneling incentive, good corporate governance dan mekanisme bonus. Sedangkan sisanya $66,5 \%$ dipengaruhi oleh variabel diluar dari pajak, tunneling incentive, good corporate governance dan mekanisme bonus.

Kata Kunci: Harga Transfer, Tunneling Incentive, Tata Kelola Yang Baik, Pajak, Mekanisme Bonus. 


\section{PENDAHULUAN}

Seiring dengan perkembangan dunia usaha dan bisnis, perusahaa-perusahaan nasional kini banyak yang meningkat menjadi perusahaan multi nasional yang kegiatan usahanya tidak hanya di satu negara saja, namun di beberapa negara lainnya.Globalisasi pasar dan perusahaan diiringi oleh perkembangan sistem informasi dan komunikasi yang kuat. Sebagai konsekuensinya, perusahaan multinasional menetapkan proses terintregrasi yang mengarah pada peningkatan jumlah transaksi antar perusahaan. Beberapa transaksi melibatkan afiliasi yang berada pada dua yurisdiksi berbeda. Perbedaan yurisdiksi dapat menimbulkan masalah, salah satunya adalah masalah tarif pajak yang berbeda setiap negara. Hal itu memicu perusahaan multinasional untuk memperkecil maupun menghindari pajak tinggi juga pajak berganda (Noviastika,2016).

Upaya dalam memperkecil pajak secara internasional dilakukan dengan transfer pricing, yaitu memperbesar harga pembelian atau biaya (over invoice) atau memperkecil harga penjualan (under invoice) (Ilyas dan Suhartono, 2009). Hal ini digunakan untuk mengalihkan keuntungan ke negara yang memiliki tarif rendah dengan memaksimalkan beban pada akhirnya mengurangi pendapatan (PriceWaterhouseCooper 2009 dalam Pramana, 2014 dalam Noviastika, 2016). Transfer pricing merupakan isu yang sensitif dalam dunia bisnis maupun ekonomi secara global, terutama dalam perpajakan. Aktivitas dari transfer pricing dilakukan oleh perusahaan multinasional akan mempengaruhi tingkat penerimaan negara dari sisi pajak baik secara langsung maupun tidak langsung. Transfer pricing dilakukan dengan menentukan jumlah penghasilan yang didapat masing-masing perusahaan yang terlibat dan penerimaan pajak penghasilan di negara pengekspor maupun negara pengimpor.

Praktik transfer pricing juga telah dilakukan oleh PT Toyota Motor Manufacturing Indonesia pada saat itu Wajib Pajak melakukan permohonan pengembalian pajak (restitusi) untuk Tahun Pajak 2005, 2007 dan 2008. Atas permohonan tersebut DJP melakukan pemeriksaan, pada Tahun 2004 laba bruto PT Toyota turun lebih dari 30\%, dari Rp 1,5 triliun (2003) menjadi Rp 950 miliar. Selain itu perbandingan antara laba kotor dengan tingkat penjualanjuga mengalami penurunan, dari sebelumnya 14,59\% pada tahun2003 menjadi hanya 6,58\% pada tahun 2004 . Sebelum restrukturisasi rasio gross margin PT Toyota Motor Manufacturing Indonesia mengalami peningkatan $11 \%$ hingga $14 \%$ per tahun. Namun setelah restrukturisasi 
hanya sekitar 1,8\% hingga 3\% per tahun. Jika PT Toyota Astra Motor (perusahaan agen tunggal pemegang merek) di gabung dengan PT Toyota Motor Manufacturing Indonesia rasio gross margin masih sebesar 7\%.Berdasarkan hasil pemeriksaan pajak SPT Toyota, petugas pajak menyimpulkan penyebab turunnya rasio gross margin adalah terjadinya transfer pricing dengan harga diluar prinsip kewajaran dan kelaziman usaha serta pembayaran royalti yang tidak wajar (Rudi Henrayana, 2016).

Ada beberapa alasan atau faktor perusahaan multinasional melakukan transfer pricing. Salah satunya adalah alasan pajak. Menurut (Suryana dalam Yuniasih et al.2012), tujuan dilakukan transfer pricing adalah untuk mengakali jumlah laba perusahaan sehingga pajak yang dibayar dan dividen yang dibagikan menjadi rendah. Hal ini membuktikan bahwa motivasi pajak memiliki peran yang tinggi dalam mempengaruhi keputusan melakukan transfer pricing.

Faktor lain yang memungkinkan perusahaan dalam mengambil keputusan melakukan transfer pricing adalah tunneling. Tunneling adalah pemindahan sumber daya dari dalam perusahaan ke pemegang saham pengendali (Johnson, 2000, dalam Noviastika,2016). Pemindahan sumber daya dapat dilakukan dengan berbagai cara, salah satunya adalah dengan melalui transfer pricing. Lo et al., (2010) dalam Noviastika (2016) menyatakan bahwa kosentrasi kepemilikan oleh pemerintah di Tiongkok berpengaruh terhadap keputusan transfer pricing dimana perusahaan bersedia mengorbankan penghematan pajak untuk tunneling keuntungan ke perusahaan induk.

Faktor lain yang mampu mempengaruhi perusahaan melakukan transfer pricing adalah tata kelola perusahaan (corporate governance). Good corporate governance menjalankan dan mengembangkan perusahaan dengan bersih, patuh pada hukum yang berlaku dan peduli terhadap lingkungan yang dilandasi nilai-nilai sosial budidaya yang tinggi. Unsur-unsur dari good corporate governance di antaranya; pemegang saham, direksi, dewan komisaris, manajer, karyawan, komite audit, investor, akuntan publik, kualitas audit dan lain sebagainya (Sutedi, 2012 dalam Noviastika,2016). Perusahaan yang memiliki tata kelola yang baik akan mempertimbangkan segala kegiatannya, terutama untuk kegiatan yang menyimpang dari aturan. Hal ini dapat memungkinkan good corporate governance dapat mempengaruhi perusahaan dalam melakukan transfer pricing. Pada dasarnya good corporate governance dilatarbelakangi oleh agency theory yang pada dasarnya agency muncul ketika suatu perusahaan terpisah dari 
kepemilikannya.pemilik sebagai pemasok modal mendelegasikan wewenangnya atas penglolaan perusahaan kepada profesional manager. Akibatnya, kewenangan untuk menggunakan sumber daya yang dimiliki perusahaan sepenuhnya ada ditangan eksekutif. Hal itu bertindak hal yang terbaik untuk kepentingan pemilik karena adanya perbedaan kepentingan (conflict of interest). Manajer dan informasi yang dimilikinya bertindak hanya untuk menguntungkan diri sendiri dengan mengorbankan kepentingan pemilik karena manajer memiliki informasi perusahaan yang tidak dimiliki (Asymetri Information) (Wibisono,2004 dalam DJ Wibisana, 2014).

Menurut Suandy (2011), lebih dari $80 \%$ perusahaan - perusahaan multinasional (MNC) melihat harga transfer (transfer pricing) sebagai suatu isu pajak internasional utama, dan lebih dari setengah perusahaan ini mengatakan bahwa isu ini adalah isu yang paling penting. Hal ini tidak terlepas dari semakin berkembangnya globalisasi ekonomi yang ditandai dengan munculnya banyak perusahaan multinasional (Multi National Enterprise) yang beroperasi di manca negara.

Selanjutnya, keputusan untuk melakukan transfer pricing juga dipengaruhi oleh mekanisme bonus (bonus mechanism). Menurut Purwanti (2010) dalam Kiswanto (2014) bonus merupakan penghargaan yang diberikan oleh RUPS kepada anggota Direksi apabila perusahaan memperoleh laba. Sistem pemberian bonus ini akan memberikan pengaruh terhadap manajemen dalam merekayasa laba. Manajer akan cenderung melakukan tindakan yang mengatur laba bersih untuk dapat memaksimalkan bonus yang akan mereka terima. Termasuk dengan cara melakukan transfer pricing.

Pengaturan tentang transfer pricing di Indonesia tidak lepas dari prinsip yang mendasari praktik pengaturan transfer pricing yang telah menjadi kebiasaan umum untuk diterapkan di banyak negara. Prinsip utama yang dianut dalam pengaturan transfer pricing adalah diacunya konsep dalam kerangka teoritikal akuntansi yaitu prinsip arm's length transaction (PER NO. 43/ PJ./2010).

Rumusan masalah dalam penelitian ini adalah (1) Apakah pajak berpengaruh terhadap indikasi melakukan transfer pricing?, (2) Apakah Tunneling Incentive berpengaruh terhadap indikasi melakukan transfer pricing?, (3) Apakah Good Corporate Governance $(G C G)$ berpengaruh terhadap indikasi melakukan transfer pricing? Dan (4) Apakah Mekanisme Bonus berpengaruh terhadap indikasi melakukan transfer pricing? 


\section{TINJAUAN PUSTAKA}

\section{Teori Agensi}

Teori agensi adalah teori yang muncul ketika ada dua pihak yang saling terikat, dimana kedua belah pihak sepakat untuk memakai jasa. Hubungan keagenan adalah sebagai kontrak, dimana satu atau beberapa orang (principal) mempekerjakan orang atau pihak lain (agen) untuk melaksanakan sejumlah jasa dan mendelegasikan wewenang untuk mengambil keputusan. Dari sini dapat diketahui bahwa manajemen wajib mempertanggungjawabkan semua keputusan terhadap pengguna laporan keuangan, termasuk investor, stakeholders, pemegang saham, dan kreditor (Yuniasih2012).

\section{Afiliasi}

Afiliasi adalah bentuk suatu hubungan antara dua atau lebih perseroan yang didasarkan pada kepemilikan saham atau bentuk kerjasama antara dua lembaga yang masing-masing berdiri sendiri. Secara singkat, afiliasi juga bisa diartikan anggota atau cabang. Hubungan yang dimaksud adalah hubungan kepemilikan saham voting (voting stock) dan perusahaan - perusahaan yang mempunyai hubungan ini dinamakan perusahaan berafiliasi. Perseroan yang menguasai mayoritas saham voting berhak melakukan kontrol terhadap perseroan lainnya dan dikenal dengan sebutan perusahaan induk, sedangkan perusahaan yang dikontrol atau yang memiliki sebagian kecil saham voting disebut dengan perusahaan anak (Judisseno, 2005 dalam Hartati,2014).Penyerahan kewenangan dari prinsipal kepada agen menimbulkan masalah informasi asimetris antara prinsipal sebagai pemegang saham dan agen sebagai pengelola perusahaan. Sifat struktur kepemilikan dari suatu perusahaan dapat mempengaruhi jenis masalah keagenan yang besar kemungkinannya adalah konflik antara pemegang saham dan manager (Jensen dan Meckling dalam Brundy, 2014 dalam Noviastika,2016). Konflik yang timbul karena adanya ketidaksesuaian informasi, menyebabkan manajer memiliki informasi lebih banyak dibandingkan pemegang saham. Sementara ketika struktur kepemilikan terkosentrasi, dalam artian satu pihak memiliki pengendalian atas perusahaan, maka masalah keagenan yang muncul akan berbeda, yaitu dimana masalah manager dengan pemegang saham berubah menjadi 
pemegang saham mayoritas dengan pemegang saham minoritas (Clanssens et al., dalam Brundy 2014 dalam Noviastika,2016).

\section{Definisi dan Pengukuran Pajak}

Menurut Prof. Dr. P.J. Adriani dalam Ilyas dan Suhartono (2009) dalam Noviastika (2016) mengemukakan pajak adalah iuran masyarakat kepada negara (yang dapat dipaksakan) dengan tiada mendapat jasa timbal (kontraprestasi) yang langsung dapat ditunjukkan dan yang digunakan untuk membayar pengeluaran umum. Variabel pajak dalam penelitian ini diukur dengan menggunakan effective tax rate (ETR). Effective tax rate (ETR) merupakan sebuah persentase besaran tarif pajak yang ditanggung oleh perusahaan. ETR dinilai dari informasi keuangan yang dihasilkan oleh perusahaan sehingga ETR merupakan bentuk perhitungan tarif pajak pada perusahaan (Aunalal, 2011, Hanum, 2013 dalam Noviastika, 2016).

\section{Tunneling Incentive}

Tunneling merupakan istilah awal yang digunakan untuk menggambarkan kondisi pengambilan aset suatu pemegang saham non-pengendali di Republik Ceko melalui pengalihan aset dan keuntungan demi kepentingan pemegang saham pengendali (Guing dan Farahmita, 2011 dalam Noviastika, 2016). Tunneling incentive adalah suatu perilaku dari pemegang saham mayoritas yang mentransfer aset dan laba perusahaan demi keuntungan mereka sendiri, tetapi pemegang biaya dibebankan pada pemegang saham minoritas (Hartati, et al., 2014). Tunneling incentive muncul dalam dua bentuk, yaitu: yang pertama, pemegang saham pengendali dapat memindahkan sumber daya dari perusahaan ke dirinya sendiri melalui transaksi antara perusahaan dengan pemilik. Transaksi tersebut dapat dilakukan dengan penjualan aset, kontrak harga transfer kompensasi eksekutif yang berlebihan, pemberian pinjaman, dan lainnya. Bentuk kedua adalah pemegang saham pengendali dapat meningkatkan bagiannya atas perusahaan tanpa memindahkan aset melalui penerbitan saham dilutif atau transaksi keuangan lainnya yang mengakibatkan kerugian bagi pemegang saham non-pengendali (Johnson, 2000 dalan Noviastika, 2016).

Variabel tunneling incentive pada penelitian ini didasarkan pada besarnya kepemilikan saham asing yang melebihi $20 \%$ (dua puluh persen). Entitas dianggap 
memiliki pengaruh signifikan secara langsung maupun tidak langsung (contohnya melalui entitas anak) apabila menyertakan modal $20 \%$ atau lebih berdasarkan Pernyataan Standar Akuntansi Keuangan (PSAK) No. 15.

\section{Good Corporate Governance}

Menurut Cadbury dalam Sutedi, (2012) definisi dari good corporate goverance adalah mengarahkan dan mengendalikan perusahaan agar tercapai keseimbangan antara kekuatan dan kewenangan perusahaan. Adapun Center For European Policy Study (CEPS) mendefinisikan good corporate goverance sebagai seluruh sistem yang dibentuk mulai dari hak (right), proses dan pengendalian baik yang ada di dalam maupun di luar manajemen perusahaan dengan catatan hak disini adalah hak dari seluruh stakeholder dan tidak hanya dari satu stakeholder saja.

Prinsip-prinsip dalam good corporate governance menurut Sutedi adalah:

1. Transparency (Keterbukaan Informasi)

2. Accountability (Dapat dipertanggung-jawabkan)

3. Fairness (Kejujuran)

4. Sustainability (Kesinambungan)

Pelaku dari Good Corporate Governance yang digunakan dalam penelitian ini adalah kualitas audit. Pemilihan kualitas audit didasarkan pada pertimbangan dimana kualitas audit mencakup beberapa unsur yang ada di dalam Good Corporate Governance yaitu, keterbukaan, kejujuran dan akuntabilitas.

\section{Pengukuran Good Corporate Governance}

Pengukuran proksi kualitas audit yang dilihat dalam reputasi KAP.Kantor Akuntan Publik yang dinilai terintegrasi dan terpercaya adalah The Big Ten, diantaranya, PriceWaterhouseCooper $-P W C$ KAP Haryanto Sahari, Deloitte Touche Tohmatsu KAP Osman Bing Satrio, KMPG KAP Sidharta, Sidharta Widjaja, Ernest \& Young - E\&Y KAP Purwanto, Sarwoko, Sandjaja, RSM AAJ McGladrey \& Pullen, Grant Thornton, CBIZ Mayer Hoffman McCann, BDO USA, Crowe Horwath dan BKD. 


\section{Mekanisme Bonus}

Sistem kinerja mekanisme bonus memberikan pengaruh terhadap kinerja manajemen. Kane et al.,(2005) dalam Pujianingsih (2011) Niken Lailiyul (2014) dengan menggunakan mekanisme bonus dalam teori keagenan, menjelaskan bahwa kepemilikan manajemen dibawah 5 persen terdapat keinginan dari menajer melakukan manajemen laba agar mendapatkan bonus yang besar. Kepemilikan manajemen 25 persen, karena manajemen mempunyai kepemilikan yang cukup besar dengan hak pengendalian perusahaan, maka asimetri informasi menjadi berkurang. Jika manajemen melakukan pengelolaan laba secara oportunis, maka informasi tersebut dapat menyebabkan pengambilan keputusan investasi yang salah bagi investor. Sehingga perlu diketahui faktor-faktor apa saja yang mempengaruhi pengelolaan laba yang dilakukan perusahaan (Pujianingsih, 2011) Niken Lailtul (2014).

\section{Pengukuran Mekanisme Bonus}

Perusahaan yang melakukan rencana bonus di beri nilai 1 dan yang tidak di beri nilai 0 . mekanisme bonus merupakan salah satu strategi atau motif perhitungan dalam akuntansi yang tujuannya adalah untuk memberikan penghargaan kepada direksi atau manajemen dengan melihat laba perusahaan secara keseluruhan. Karena sebagai akibat dari adanya praktik transfer pricing maka tidak menutup kemungkinan akan terjadi kerugian pada salah satu divisi atau subunit.

\section{Transfer Pricing}

Transfer Pricing adalah kebijakan suatu perusahaan dalam menentukan harga transfer suatu transaksi yang dapat dibedakan menjadi dua kelompok yaitu intra company transfer pricing dan inter company transfer pricing. Intra company tranfer pricing merupakan tranfer pricingantar divisi dalam satu perusahaan, sedangkan Inter company transfer pricing merupakan transfer pricing antara dua perusahaan yang mempunyai hubungan istimewa. Kedua perusahaan tersebut dapat berada dalam satu Negara (domestic transfer pricing) dan dapat juaga berada di Negara yang berada (international transfer pricing).

Harga transfer atau transfer pricing dalam bahasa Inggris berasal dari kata transfer price sering diartikan sebagai nilai yang melekat pada pengalihan barang dan jasa yang terjadi pada suatu transaksi antara pihak yang mempunyai hubungan 
istimewa. Menurut Horngren (2008) dalam Hartati (2015), yang dimaksud dengan transfer pricing (harga transfer) adalah harga yang dibebankan satu subunit (departemen atau divisi) untuk suatu produk atau jasa yang dipasok ke sub unit yang lain di organisasi yang sama.

\section{Pengukuran Transfer Pricing}

Dalam penelitian ini, pengukuran untuk variabel transfer pricing diproksikan dengan ada atau tidaknya penjualan terhadap pihak berelasi atau yang memiliki hubungan istimewa. Penjualan terhadap hubungan istimewa diindikasikan ada transfer pricing. Harga yang ditetapkan dalam penjualan terhadap pihak berelasi atau hubungan istimewa biasanya menggunakan harga yang tidak wajar bisa dengan menaikkan atau menurunkan harga. Hubungan istimewa yang digunakan sebagai pengukur dalam penelitian ini adalah wajib pajak yang mempunyai penyertaan modal langsung atau tidak langsung paling rendah 25\% (dua puluh lima persen) pada wajib pajak lain.

\section{Pengaruh Pajak Terhadap Indikasi Melakukan Transfer Pricing}

Perusahaan multinasional melakukan perencanaan pajak dengan berbagai cara. Perencanaan pajak yang sering digunakan oleh perusahaan multinasional diantaranya, transfer pricing, thin capitalization, capital repatritaion, foriegn-exchange control, international double taxation and foreign tax credit, tax treaty protection/facilities, establishment of representative, branch or subsidiary Santoso (dalam Karisma, 2014) dan dalam Noviastika, (2016). Yuniasih et al., (2012) menemukan bahwa beban pajak yang semakin besar menyebabkan perusahaan untuk melakukan transfer pricing.

\section{$\mathrm{H}_{1}$ : Pajak berpengaruh signifikan terhadap indikasi melakukan Transfer Pricing.}

\section{Pengaruh Mekanisme Bonus Terhadap Indikasi melakukan Transfer Pricing}

Penghargaan itu dapat berupa bonus yang diberikan kepada direksi perusahaan. Dalam memberikan bonus kepada direksi, pemilik perusahaan akan melihat kinerja para direksi dalam mengelola perusahaanya.Hal ini didukung oleh pendapat Horngren (2008) dalam Hartati (2014), yang menyebutkan bahwa kompensai (bonus) direksi dilihat dari kinerja berbagai divisi atau tim dalam satu organisasi. Semakin besar laba perusahaan secara keseluruhan yang dihasilkan, maka semakin baik citra para direksi dimata pemilik perusahaan.Terdapat kecenderungan manajemen memanfaatkan transaksi 
transfer pricing untuk memaksimalkan bonus yang mereka terima jika bonus tersebut didasarkan pada laba. Jadi dapat disimpulkan bahwa manajer akan cenderung melakukan tindakan yang mengatur laba bersih dengan cara melakukan praktik transfer pricing agar dapat memaksimalkan bonus yang mereka terima.

\section{$\mathrm{H}_{2}:$ Mekanisme bonus berpengaruh signifikan terhadap keputusan Transfer} Pricing.

\section{Pengaruh Tunneling Incentive Terhadap Indikasi Melakukan Transfer Pricing}

Tunneling merupakan perilaku pengalihan aset dan laba perusahaan untuk kepentingan pemegang saham mayoritas yang mengendalikan pemegang saham minoritas (Johnson dalam Aharony et al., 2010 dalam Noviastika, 2016). Contoh tunneling incentive adalah tidak membagikan deviden, menjual aset atau sekuritas dari perusahaan yang mereka kontrol ke perusahaan lain yang mereka miliki dengan harga di bawah harga pasar, dan memilih anggota keluarganya yang tidak memenuhi kualifikasi untuk menduduki posisi penting di perusahaan (La Porta dalam Kharisma, 2014 dalam Noviastka, 2016). Tunneling merupakan perilaku manajemen atau pemegang saham mayoritas yang mentransfer aset dan profit perusahaan untuk kepentingan mereka sendiri, namun biaya dibebankan kepada pemegang saham minoritas (Zhang, 2004 dalam Hartati, 2012). Beberapa bentuk tunneling adalah loan guarantees, penjualan produk dibawah harga pasar, manipulasi pembayaran dividen.

\section{$\mathrm{H}_{3}$ : Tunneling Incentive berpengaruh signifikan pada indikasi melakukan Transfer} Pricing.

\section{Pengaruh Good Corporate Governance (GCG) Terhadap Indikasi melakukan Transfer Pricing}

Salah satu komponen dari Good Coporate Governance (GCG) yang digunakan dalam penelitian ini adalah kualitas audit. Hal tersebut dapat dilakukan dengan cara melaporkan hal-hal yang terkait dengan perpajakan pada pasar modal dan RUPS. Berdasarkan penelitian Annisa dan Kurniasih (2012), kualitas audit mempengaruhi pelaksanaan tax avoidance. Apabila suatu perusahaan diaudit oleh oleh Kantor Akuntan 
Publik (KAP) The Big Ten maka akan semakin sulit melakukan kebijakan pajak agresif. Semakin berkualitas audit suatu perusahaan, maka perusahaan cenderung tidak akan melakukan manipulasi laba untuk kepentingan perpajakan (Chai dan Liu dalam Annisa dan Kurniasih, 2012). Salah satu cara dalam tax avoidance adalah transfer pricing.

\section{H4: Good Corporate Governance berpengaruh signifikan terhadap indikasi melakukan Transfer Pricing.}

\section{Kerangka Pemikiran}

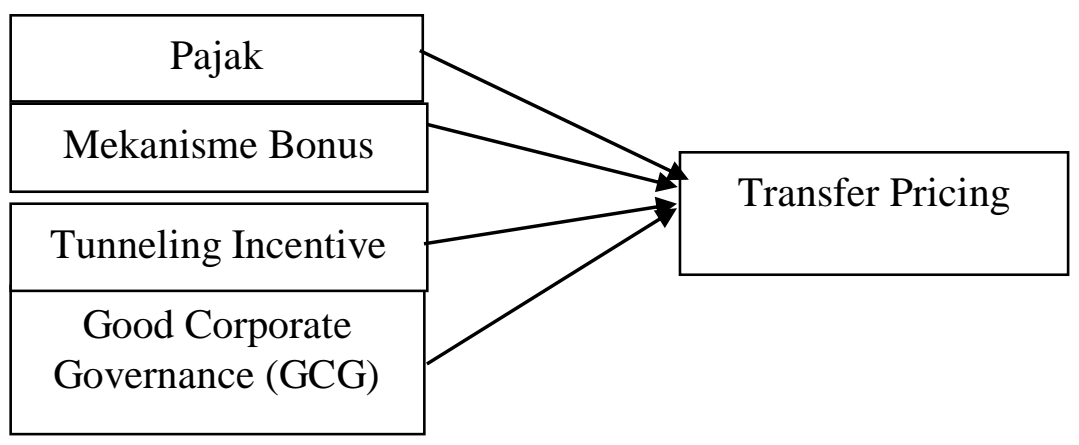

\section{METODE PENELITIAN}

Jenis penelitian yang digunakan dalam penelitian ini adalah penelitian eksplanatori dengan pendekatana kuantitatif. Menurut Zulganef (2013:23), bahwa penelitian explanatory adalah penelitian yang bertujuan menelaah kausalitas antar variabel yang menjelaskan suatu fenomena tertentu. Dalam penelitian ini, hubungan kausal antara pajak, tunneling incentive, good corporate governance, dan mekanisme bonus dengan indikasi melakukan transfer pricing. Pengambilan sampel dilakukan dengan purposive sampling. Sampel dipilih berdasarkan kriteria yang telah ditentukan. Sampel yang didapatkan sebesar 42 perusahaan selama kurun waktu tiga tahun (2013-2015) yaitu sebanyak 126 perusahaan. 


\section{HASIL PENELITIAN DAN PEMBAHASAN}

Hasil dari penelitian yang telah dilakukan sebagai berikut :

\section{Hasil uji regresi logistic}

Bentuk persamaan regresi logistik dapat ditulis sebagai berikut :

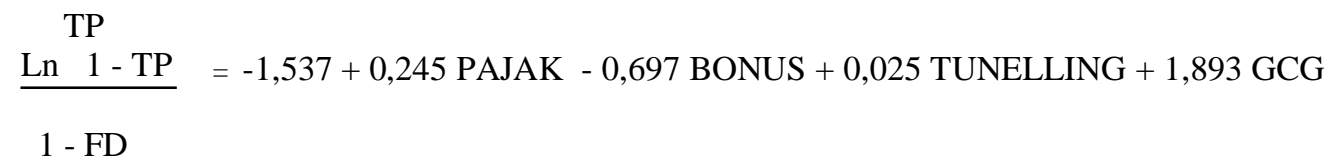

1. Konstanta sebesar -1,537(lebih kecil dari 0,5) yang berarti bahwa jika tidak dipengaruhi oleh 4 prediktor dalam model penelitian ini, maka perusahaan akan cenderung tidak melakukan transfer pricing (kearah $\mathrm{TP}=0$ ).

2. Koefisien variabel Pajak diperoleh sebesar 0,245. Arah koefisien positif berarti bahwa pada perusahaan yang membayar pajak yang lebih rendah cenderung tidak melakukan transfer pricing.

3. Koefisien variabel skema bonus diperoleh sebesar -0,697. Arah koefisien negatif berarti bahwa pada perusahaan yang memiliki skema bonus yang lebih besar maka perusahaan cenderung tidak melakukan transfer pricing.

4. Koefisien variabel Tunelling sebesar 0,025. Arah koefisien positif berarti bahwa pada perusahaan yang memiliki tunelling yang lebih besar maka probabilitas perusahaan akan cendereung melakukan transfer pricing.

5. Koefisien variabel GCGsebesar 1,893. Arah koefisien positif berarti bahwa pada perusahaan yang memiliki GCG yang lebih baik maka probabilitas perusahaan akan cendereung melakukan transfer pricing.

\section{HASIL UJI HIPOTESIS}

\section{Kelayakan Model Regresi}

Hasil pengujian kesamaan model prediksi dengan observasi diperoleh nilai chi square sebesar 13,952 dengan signifikansi sebesar 0,083.Dengan nilai signifikansi yang lebih besar dari 0,05 maka berarti tidak diperoleh adanya perbedaan antara data estimasi model regresi logistik dengan data observasinya. Hal ini berarti bahwa model tersebut sudah tepat dengan tidak perlu adanya modifikasi model. 


\section{Keseluruhan Model Omnibus test (Overall test)}

Pada blok awal (beginning block) yaitu pada model hanya dengan konstanta, diperoleh nilai -2 log likelihood sebesar 165,518. Pada pengujian pada blok 1 atau pengujian dengan memasukkan seluruh prediktor diperoleh nilai -2 log likelihood sebesar 130,302. Dengan demikian terjadi penururunan -2 log likelihood yang cukup besar setelah menggunakan 4 variabel. Dengan demikian model dengan 4 prediktor menunjukkan sebagai model yang lebih baik.

\section{Koefisien Determinasi}

Besarnya estimasi penggantian auditor yang dapat dijelaskan oleh variablevariabel bebasnya dapat diperoleh dalam nilai $\mathrm{R}^{2}$ sebagai berikut : Nilai $\mathrm{R}^{2}$ yang diukur dengan Nagelkerke R Square diperoleh sebesar 0,335. Hal ini berarti bahwa 33,5\% transfer pricing dapat dijelaskan oleh variable yaitu rasio agresivitas pajak, skema bonus dan tunellingserta GCG. Sedangkan sisanya sebesr 66,5\% transfer pricing dipengaruhi oleh variabel lain.

\section{Hasil Pengujian Hipotesis}

Berdasarkan penghitungan dengan menggunakan SPSS diperoleh hasil sebagai berikut:

\section{Pengaruh Pajak terhadap Transfer Pricing}

Pengujian pengaruh variabel Agresivitas pajak terhadap probabilitas melakukan transfer pricing diperoleh nilai Wald sebesar 0,063 dengan signifikansi sebesar 0,802. Dengan nilai signifikansi yang berada di atas 0,05, maka dengan demikian dapat disimpulkan bahwa variabel agresivitas pajak tidak memiliki pengaruh yang signifikan terhadap probabilitas perusahaan melakukan transfer pricing. Hal ini berarti bahwa

\section{Hipótesis 1 ditolak.}

\section{Pengaruh Skema Bonus terhadap Transfer Pricing}

Pengujian pengaruh variabel skema bonus terhadap probabilitas melakukan transfer pricing diperoleh nilai Wald sebesar 2,417 dengan signifikansi sebesar 0,120. Dengan nilai signifikansi yang berada di atas 0,05, maka dengan demikian dapat disimpulkan bahwa variabel skema bonus tidak memiliki pengaruh yang signifikan 
terhadap probabilitas perusahaan melakukan transfer pricing. Hal ini berarti bahwa Hipótesis 2 ditolak.

\section{Pengaruh Tunelling Incentive terhadap Transfer Pricing}

Pengujian pengaruh variabel Tunelling Incentive terhadap probabilitas melakukan transfer pricing diperoleh nilai Wald sebesar 6,205 dengan signifikansi sebesar 0,013. Dengan nilai signifikansi yang berada di bawah 0,05, maka dengan demikian dapat disimpulkan bahwa variabel Tunelling Incentive memiliki pengaruh yang signifikan terhadap probabilitas perusahaan melakukan transfer pricing. Hal ini berarti bahwa Hipótesis 3 diterima.

\section{Pengaruh GCG terhadap Transfer Pricing}

Pengujian pengaruh variabel GCG terhadap probabilitas melakukan trnsfer pricing diperoleh nilai Wald sebesar 15,979 dengan signifikansi sebesar 0,000. Dengan nilai signifikansi yang berada di bawah 0,05 , maka dengan demikian dapat disimpulkan bahwa variabel GCG memiliki pengaruh yang signifikan terhadap probabilitas perusahaan melakukan transfer pricing. Hal ini berarti bahwa Hipótesis 4 diterima.

\section{PEMBAHASAN HASIL PENELITIAN}

\section{Pengaruh pajak terhadap transfer pricing}

Hasil pengujian mendapatkan bahwa ETR tidak memiliki pengaruh yang signifikan terhadap transfer pricing. Hal ini menunjukkan bahwa adanya pajak yang dilakukan oleh perusahaan dengan membayar pajak yang lebih rendah maka parusahaan menunjukkan tidak melakukan transfer pricing. Transfer pricing dalam hal ini dilakukan dengan mentransfer beberapa harga pada perusahaan yang berafiliasi atau yang diantaranya adalah anak cabang.

\section{Pengaruh Skema Bonus terhadap Transfer Pricing}

Hasil pengujian mendapatkan bahwa skema bonus tidak memiliki pengaruh yang signifikan terhadap transfer pricing. Hal ini menunjukkan bahwa perusahaan yang memiliki skema bonus tidak menunjukkan memiliki probabilits yang besar untuk melakukan transfer pricing.Perusahaan yang memiliki skema bonus ditunjukkan dengan 
adanya kenaikan laba bersih yang diperoleh perusahaan. Dengan peningkatan laba bersih tersebut maka perusahaan memiliki kebijakan untuk memiliki skema bonus bagi manajer. Namun demikian adanya skema bonus tidak berkaitan secara langsung dengan transfer pricing yang dilakukan oleh perusahaan.

\section{Pengaruh Tunelling terhadap transfer pricing}

Hasil pengujian mendapatkan bahwa tunelling perusahaan memiliki pengaruh yang signifikan terhadap transfer pricing dengan arah positif. Hal ini menunjukkan bahwa perusahaan dengan tunelling yang besar akan cenderung melakukan transer pricing. Perusahaan yang memiliki tunelling yang lebih besar menunjukkan bahwa perusahaan dikendalikan oleh pemegang saham asing yang lebih besar. Kondisi demikian menjadikan bahwa kebijakan perusahaan tidak lepas dari negara asal pemegang saham pengendali tersebut.

\section{Pengaruh GCG terhadap transfer pricing}

Hasil pengujian mendapatkan bahwa GCG perusahaan memiliki pengaruh yang signifikan terhadap transfer pricing dengan arah positif. Hal ini menunjukkan bahwa perusahaan dengan Good Corporate Governance yang baik akan cenderung melakukan transer pricing. Perusahaan yang memiliki GCG yang lebih besar menunjukkan bahwa perusahaan diaudit oleh KAP Big 4. Kondisi demikian menjadikan bahwa kebijakan perusahaan tidak lepas dari negara asal pemegang saham pengendali tersebut. KAP Big 4 yang besar menjadikan kemungkinan perusahaan melakukan transaksi dengan pihakpihak beralasi akan semakin besar, khususnya dengan pihak-pihak luar cabang perusahaan atau relasi istimewa perusahaan khususnya dengan negara dengan tingkat pajak yang lebih rendah dibanding tingkat pajak di Indonesia.

\section{KESIMPULAN DAN SARAN}

\section{Kesimpulan}

Berdasarkan hasil penelitian maka dapat ditarik kesimpulan sebagai berikut:

Agresivitas pajak ETR tidak memiliki pengaruh yang signifikan terhadap transfer pricing. Perusahaan yang membayar pajak yang lebih rendah cenderung tidak melakukan transfer pricing. Skema bonus perusahaan tidak memiliki pengaruh yang 
signifikan terhadap keputusan melakukan transfer pricing. TunellingIncentive perusahaan memiliki pengaruh positif yang signifikan terhadap transfer pricing yang berarti perusahaan yang memiliki kepemilikan saham pengendali asing yang lebih besar akan cenderung melakukan transfer pricing. Good Corporate Governance perusahaan memiliki pengaruh positif yang signifikan terhadap transfer pricing yang berarti perusahaan yang memiliki Good Corporate Governance yang baik akan cenderung melakukan transfer pricing.

\section{Saran}

Saran yang dapat diberikan berkaitan dengan hasil penelitian ini adalah sebagai berikut : Perlunya memberikan perhatian khusus terhadap fenomena manajemen laba pada pajak melalui pelaksanaan transparansi pelaporan keuangan yang lebih baik. Bagi akademis, hendaknya mempelajari tentang variabel-variabel yang tidak berpengaruh dan variabel yang berpengaruhterhadap keputusan melakukan transfer pricing, sehingga kedepannya agar diperoleh hasil yang maksimal. Bagi perusahaan, diharapkan untuk dapat meminimalkan praktik transfer pricing agar tidak merugikan negara,salah satunya dengan membayar pajak secara jujur dan rutin. Bagi pemerintah, penelitian ini diharapkan menjadi bahan pertimbangan untuk membuat suatu peraturan yng mewajibkan perusahaan untuk tidak melakukan praktik transfer pricing dikarenakan dilihat dari beberapa sisi pembayaran pajak yang sudah banyak dimanipulasi agar pembayaran pajaknya lebih rendah dari yang semestinya, pihak perusahaan seharusnya lebih memperhatikan tanggung jawab sosialnya kepada masyarakat.

\section{Keterbatasan Penelitian}

Penelitian ini tidak lepas dari keterbatasan-keterbatasan yang dapat menjadikan penelitian ini menjadi bias,keterbatasan penelitian ini adalah hanya:

1. Menghasilkan koefisien determinasi sebesar 33,5\%. Oleh karena itu masih ada variabel lain yang berpengaruh terhadap keputusan perusahaan dalam melakukan transfer pricing. Salah satunya adalah ukuran perusahaan. Ukuran perusahaan merupakan nilai yang menunjukkan besar kecilnya perusahaan.

2. Skala pengukuran variabel dependen (transfer pricing) menggunakan kepemilikan saham diatas $20 \%$, sedangkan untuk syarat melakukan transfer 
pricing menurut UU PPh No 36 Tahun 2008 adalah perusahaan yang memiliki saham atau penyertaan modal sebesar $25 \%$ atau lebih secara langsung atau tidak langsung.

\section{DAFTAR PUSTAKA}

Colgan, P. M. 2001. Agency theory ang corporate governance : A review of the literature from UK perspektive. Working paper.

Ervina, Erzi. 2014. Pengaruh good corporate governance terhadap kinerja keuangan perbankan syariah di Indonesia. Artikel Publikasi Ilmiah Universitas Muhammadiyah Surakarta.

Ghozali, imam. 2011. Aplikasi analisis multivariete dengan program ibm spss 16. Semarang : badan penerbit Universitas Diponegoro.

Hartati, Winda, Desmiyati, Nur Azlina. 2014. Analisis pengaruh pajak dan mekanisme bonus terhadap keputusan transfer pricing(studi empiris pada seluruh perusahaan yang listing Di bursa efek indonesia). Jurnal SNA 17 mataram.

Hartati, Winda, Desmiyati, Julita. 2015.Tax Minimization, Tunneling Incentive dan Mekanisme Bonus terhadap Keputusan Transfer Pricing Seluruh Perusahaan yang Listing di Bursa Efek Indonesia. Jurnal SNA 18 Universitas Sumatra Utara Medan.

Martasari. 2015. Pengaruh karakteristik keuangan dan nonkeuangan terhadap transfer pricing pada perusahan Indonesia. Jurnal Akuntansi Universitas Diponegoro.

Heru Pramana, Aviandika. 2014. Pengaruh Pajak, Bonus Plan, Tunneling Incentive, dan Dept Covenant terhadap Keputusan Perusahaan untuk melakukan Transfer Pricing. Jurnal Akuntans Universitas Diponegoro.

Kiswanto, Nancy, dan Anna Purwaningsih. 2014. Pengaruh pajak, kepemilikan asing dan ukuran perusahaan terhadap transfer pricing pada perusahaan manufaktur Di bursa efek indonesia Tahun 2010-2013.

Mulyadi. 2001. Akutansi manajemen. Jakarta : salemba empat.

Noviastika F, Mayowan, Karjo.2016.Pengaruh Pajak, Tunneling Incentive, dan Good Corporate Governance (GCG) terhadap Indikasi melakukan Transfer Pricing pada Perusahaan Manufaktur yang terdaftar di Bursa Efek Indonesia (Studi pada Bursa Efek Indonesia yang berkaitan dengan Perusahaan Asing)

Nurhayati, Dewi, Indah. 2013. Evaluasi atas perlakuan perpajakan terhadap transaksi transfer pricing pada perusahaan multinasional di Indonesia. Jurnal Manajemen Akutansi Vol.2. No.1.

Salsalina Linda, Ita.2012. Aspek Perpajakan dalam Transfer Pricing dan Problematika Praktik Penghindaran Pajak (Tax Avoidance). Jurnal Akuntansi Universitas Kristen Maranatha, Bandung.

Sasmitha, Melanie. 2015. Aspek Perpajakan dalam Transfer Pricing.

Wafiroh Niken, Lailiyul, Nindya Hapsari, Niken. 2014.. Pajak, tunneling incentive dan mekanisme bonus terhadap keputusan transfer pricing. Jurnal Akuntansi Universitas Islam Negeri Maulana Malik Ibrahim.

www.idx.co.id 
www. Saham ok.

Yuniasih, wayan, Ni, Ni ketut rasmini dan made gede wirakusuma. 2012. Pengaruh pajak dan tunnelling incentive pada keputusan transfer pricing perusahaan manufaktur yang listing Di bursa efek indonesia. Jurnal Universitas Udayana. 